\title{
Investigation of Pb-Sr and Pb-Ca Binary Alloys as Grids for Lead-Acid Batteries
}

\author{
Zhongfei $\mathrm{Wu}^{1, \#}$, Chen $\mathrm{Hu}^{2, \#}$, Juyi $\mathrm{Mu}^{2}$, Zhaoqin Sun ${ }^{2}$, Ruirui Zhao ${ }^{1,3, *}$,Hongyu Chen ${ }^{1,3, *}$ \\ ${ }^{1}$ School of Chemistry and Environment, South China Normal University, Guangzhou, Guangdong, \\ 510006, China \\ ${ }^{2}$ State Key Laboratory of Operation and Control of Renewable Energy \& Storage Systems, China \\ Electric Power Research Institute, Beijing, 100192, China \\ ${ }^{3}$ Base of Production, Education \& Research on Energy Storage and Power Battery of Guangdong \\ Higher Education Institutes, Guangzhou, Guangdong, 510006, China \\ *E-mail: zhaoruirui@m.scnu.edu.cn; hychen@scnu.edu.cn \\ "These authors contribute equal to this work
}

doi: $10.20964 / 2019.09 .32$

Received: 2 May 2019 / Accepted: 21 June 2019 / Published: 31 July 2019

The grid is one of the most important components in lead-acid configuration, thus searching suitable alloys to meet the requirement of the grid is vital and urgent. Considering the similar chemical properties of $\mathrm{Sr}$ to $\mathrm{Ca}$, we employed $\mathrm{Sr}$ element as a new dopant into the lead matrix, and the detailed properties of this novel binary $\mathrm{Pb}-\mathrm{Sr}$ alloys are studied. Combining the results from hydrogen/oxygen evolution reaction (HER/OER) study, anti-corrosion investigations under constant potential or current, it can be concluded that this new dopant is not suitable to be used as a sole additive to the grid for a lead-acid battery. The Sr element may accelerate the electrochemical reaction occurred onto the alloys, resulting in deteriorated anti-corrosive properties. Furthermore, the behaviors of the alloys operated under different temperatures (Room temperature and $60^{\circ} \mathrm{C}$ ) are also studied in this research, aiming to provide some useful guidance in alloy design and application.

Keywords: lead-acid battery; lead alloys; grids; corrosion properties

\section{$\underline{\text { FULL TEXT }}$}

(C) 2019 The Authors. Published by ESG (www.electrochemsci.org). This article is an open access article distributed under the terms and conditions of the Creative Commons Attribution license (http://creativecommons.org/licenses/by/4.0/). 